Published in: Journal of Applied Physics, vol. 120, p. 105103, 2016.

DOI: $10.1063 / 1.4962262$

\title{
Formation of Silicon Nanocrystals in Silicon Carbide Using Flash Lamp Annealing
}

$\underline{\text { Charlotte Weiss }}{ }^{1}$, Manuel Schnabel ${ }^{1}$, Slawomir Prucnal ${ }^{2}$, Johannes Hofmann ${ }^{1,}$ Andreas Reichert ${ }^{3}$, Tobias Fehrenbach $^{1}$, Wolfgang Skorupa ${ }^{2}$, Stefan Janz ${ }^{1}$

${ }^{1}$ Fraunhofer Institute for Solar Energy Systems, Heidenhofstraße 2,79110 Freiburg, Germany.

${ }^{2}$ Institute of Ion Beam Physics and Materials Research, Helmholtz-Zentrum Dresden-Rossendorf P.O. Box 510119, 01314 Dresden, Germany.

${ }^{3}$ Now with: Department of Radiology, Division of Medical Physics, University of Freiburg, Freiburg, Germany 
Published in: Journal of Applied Physics, vol. 120, p. 105103, 2016.

DOI: $10.1063 / 1.4962262$

\section{0) ABSTRACT}

During the formation of $\mathrm{Si}$ nanocrystals $(\mathrm{Si} \mathrm{NC})$ in $\mathrm{Si}_{x} \mathrm{C}_{1-x}$ layers via tube furnace solid-phase crystallization, the unintended formation of nanocrystalline $\mathrm{SiC}$ reduces the minority carrier lifetime and therefore the performance of $\mathrm{Si}_{x} \mathrm{C}_{1-x}$ as an absorber layer in solar cells. A significant reduction in the annealing time may suppress the crystallization of the $\mathrm{SiC}$ matrix while maintaining the formation of Si NC. In this study, we investigated the crystallization of stoichiometric $\mathrm{SiC}$ and $\mathrm{Si}$-rich $\mathrm{SiC}$ using conventional rapid thermal annealing (RTA) and nonequilibrium millisecond range flash lamp annealing (FLA). The investigated $\mathrm{Si}_{x} \mathrm{C}_{1}$ $x$ films were prepared by plasma-enhanced chemical vapor deposition (PECVD) and annealed at temperatures from $700^{\circ} \mathrm{C}$ to $1100^{\circ} \mathrm{C}$ for RTA and at flash energies between $34 \mathrm{~J} / \mathrm{cm}^{2}$ and $62 \mathrm{~J} / \mathrm{cm}^{2}$ for FLA. Grazing incidence X-ray diffraction and Fourier transformed infrared spectroscopy were conducted to investigate hydrogen effusion, $\mathrm{Si}$ and $\mathrm{SiC} \mathrm{NC}$ growth and $\mathrm{SiC}$ crystallinity. Both the $\mathrm{Si}$ content and the choice of the annealing process affect the crystallization behavior. It is shown that under certain conditions, FLA can be successfully utilized for the formation of $\mathrm{Si} \mathrm{NC}$ in a $\mathrm{SiC}$ matrix, which closely resembles $\mathrm{Si}$ $\mathrm{NC}$ in a SiC matrix achieved by RTA. The samples must have excess $\mathrm{Si}$, and the flash energy should not exceed $40 \mathrm{~J} / \mathrm{cm}^{2}$ and $47 \mathrm{~J} / \mathrm{cm}^{2}$ for $\mathrm{Si}_{0.63} \mathrm{C}_{0.37}$ and $\mathrm{Si}_{0.77} \mathrm{C}_{0.23}$ samples, respectively. Under these conditions, FLA succeeds in producing Si NC of a given size in less crystalline SiC than RTA does. This result is discussed in terms of nucleation and crystal growth using classical crystallization theory. For FLA and RTA samples, an opposite relationship between NC size and Si content was observed and attributed either to the dependence of $\mathrm{H}$ effusion on $\mathrm{Si}$ content or to the optical absorption properties of the materials, which also depend on the Si content.

Keywords: Silicon nanocrystals, SiC, tandem solar cells, FLA, RTA, GIXRD, FTIR 
Published in: Journal of Applied Physics, vol. 120, p. 105103, 2016.

DOI: $10.1063 / 1.4962262$

I) INTRODUCTION

The concept of multijunction solar cells exceeding the Shockley-Queisser limit in efficiency is a success story. III-V Semiconductor cells reach efficiencies of more than $38.8 \%$ under one sun [1]. For low-cost Sibased a-Si/ $/ \mathrm{c}-\mathrm{Si}$ cells, the highest reported efficiency of $13.6 \%$ lies above the corresponding efficiencies of a-Si and $\mu \mathrm{c}-\mathrm{Si}$ single junction cells [1]. Between these two record efficiencies, there is still a broad research field of cost reduction in the case of III-V semiconductors and efficiency as well as quality enhancement in the case of Si. One approach is the all-Si tandem solar cell combining a monocrystalline Si bottom cell with a Si nanocrystal ( $\mathrm{Si} \mathrm{NC)} \mathrm{top} \mathrm{cell} \mathrm{[2].} \mathrm{In} \mathrm{this} \mathrm{structure,} \mathrm{the} \mathrm{band} \mathrm{gap} \mathrm{of} \mathrm{the} \mathrm{top} \mathrm{cell} \mathrm{has} \mathrm{to} \mathrm{exceed} \mathrm{the} \mathrm{band}$ gap of the crystalline Si bottom cell. This condition can be realized with the help of the quantum confinement effect in Si NC, which will occur if the crystals are embedded in a dielectric matrix [3]. 3C-SiC is a suitable matrix material with a band gap of $2.4 \mathrm{eV}$ [4], resulting in relatively small band offsets to $\mathrm{Si}$ [5]. Therefore, the material provides the necessary potential well structure for the quantum confinement effect in Si NC on the one hand, while it is sufficiently conductive to act as a solar cell absorber material on the other hand. For this reason, several research groups produce $\mathrm{Si} \mathrm{NC}$ in a $\mathrm{SiC}$ matrix by the deposition of amorphous $\mathrm{Si}_{x} \mathrm{C}_{1-x}(x>1)$ layers either by sputtering or by plasma-enhanced chemical vapor deposition (PECVD) [611]. During the subsequent annealing step at temperatures up to $1100^{\circ} \mathrm{C}$, phase separation between $\mathrm{Si}$ and $\mathrm{SiC}$ and solid-phase crystallization occur. In the aforementioned studies, two main challenges are reported: the size control of $\mathrm{Si} \mathrm{NC}$ and the co-crystallization of $\mathrm{Si}$ and $\mathrm{SiC}$. The former is crucial for the quantum confinement effect, and the latter causes a high defect density and therefore extremely short lifetimes, making a definitive proof of quantum confinement - to the best of the authors' knowledge - impossible until now. In a prior study, we showed that the $\mathrm{Si} \mathrm{NC}$ size can be controlled by the Si content of the $\mathrm{Si}_{x} \mathrm{C}_{1-x}$ layers [12]. In the present work, we tried to reduce $\mathrm{SiC}$ crystallization by reducing the annealing time. Wan et al. [13] reported a positive effect on $\mathrm{Si}$ crystallization for co-sputtered $\mathrm{Si}_{x} \mathrm{C}_{1-x}$ layers by reducing the annealing time from $60 \mathrm{~min}$ via furnace annealing to $2 \mathrm{~min}$ via rapid thermal annealing (RTA). Flash lamp annealing (FLA), a nonequilibrium thermal process that operates in the millisecond range, has been successfully used to crystallize relatively thick $\mathrm{SiC}$ and $\mathrm{Si}$ layers. Ohdaira et al. [14, 15] used FLA for $10 \mathrm{~ms}$ 
Published in: Journal of Applied Physics, vol. 120, p. 105103, 2016.

DOI: $10.1063 / 1.4962262$

to crystallize $100 \mu \mathrm{m}$ thick a-Si, whereas Skorupa et al. [16] showed that 3C-SiC on Si can be made by FLA for $20 \mathrm{~ms}$. On our PECVD deposited a-Si $\mathrm{C}_{1-x}: \mathrm{H}$ layers, we performed an RTA process for $2 \mathrm{~min}$ at different temperatures and compared the result to that obtained for samples annealed by FLA for $20 \mathrm{~ms}$ at different flash energies. Three different compositions of as-deposited (as-dep) a-Si $\mathrm{C}_{1-x}: \mathrm{H}$ layers were investigated: $x=0.50, x=0.63$ and $x=0.77$. The crystallization process was studied by grazing incidence X-ray diffraction (GIXRD). We consider the appearance of these patterns to establish a correspondence between FLA energies and RTA temperatures. The diffraction patterns were also used to determine the $\mathrm{Si}$ and $\mathrm{SiC}$ NC size. With the help of Fourier transformed infrared spectroscopy (FTIR), it was possible to observe the temperature dependence of hydrogen effusion (H effusion) and to compare the SiC crystallinity after RTA and FLA. The effects of layer composition and annealing procedure on the crystallization process are discussed in detail in terms of $\mathrm{H}$ effusion, nucleation and crystal growth. 
Published in: Journal of Applied Physics, vol. 120, p. 105103, 2016.

DOI: $10.1063 / 1.4962262$

\section{II) EXPERIMENTAL}

\subsection{Sample Preparation}

The layers used for RTA and FLA in this study were deposited on $250 \mu \mathrm{m}$ thick p-type FZ silicon substrates, (100)-oriented with a resistivity of $10 \Omega \mathrm{cm}$. Fused silica (Suprasil ${ }^{\circledR} 1$ ) substrates measuring $1 \mathrm{~mm}$ thick were used for spectrophotometry measurements on as-dep samples. All substrates were cleaned in hot $\mathrm{HNO}_{3}$ and dilute HF before film deposition. The fused silica was subjected to an additional cleaning step in hot $\mathrm{HCl} / \mathrm{H}_{2} \mathrm{O}_{2}$ solution followed by a second $\mathrm{HF}$ etching step before film deposition.

Film deposition was performed by PECVD in a Roth\&Rau AK400 reactor. The substrate temperature was kept at $270^{\circ} \mathrm{C}$ during deposition and the pressure at 0.3 mbar. The plasma power density was $100 \mathrm{~mW} / \mathrm{cm}^{2}$, and the plasma frequency was $13.56 \mathrm{MHz}$. The stoichiometry of the deposited hydrogenated amorphous silicon carbide $\left(\mathrm{a}-\mathrm{Si}_{x} \mathrm{C}_{1-x}: \mathrm{H}\right)$ was adjusted by varying the gas fluxes of silane $\left(\mathrm{SiH}_{4}\right)$, methane $\left(\mathrm{CH}_{4}\right)$ and hydrogen $\left(\mathrm{H}_{2}\right)$. The three different layer compositions of $x=0.50, x=0.63$ and $x=0.77$ used in this work were previously determined by Rutherford backscattering spectrometry with an accuracy of $1 \%$ [17]. The associated gas fluxes can be found in our previous work [12].

The intended thickness of the as-dep layers was approximately $200 \mathrm{~nm}$. The deposition rate was confirmed on test samples with the help of spectral ellipsometry. During RTA and FLA, a thickness reduction of nearly $30 \%$ occurs because of $\mathrm{H}$ effusion and reorganization of the atoms. The resulting thicknesses were measured based on scanning electron microscopy (SEM) images of the layers' cross sections.

\section{$2.2 \quad$ Rapid Thermal Annealing (RTA)}

RTA was conducted in an RTP Sol Invictus 156 PV tool from Centrotherm with a pyrometer for temperature monitoring. The samples were placed on a 4" FZ Si support wafer, and the front side was heated by the halogen lamp field located above. The annealing temperatures, which varied between $700^{\circ} \mathrm{C}$ and $1100^{\circ} \mathrm{C}$, were reached without a preanneal step at a heating rate of $50^{\circ} \mathrm{C} / \mathrm{s}$ and a plateau time of $2 \mathrm{~min}$ for all samples. The entire annealing process was completed under a nitrogen flow of $51 / \mathrm{min}$. Only layers on Si substrates were treated by RTA. 
Published in: Journal of Applied Physics, vol. 120, p. 105103, 2016.

DOI: $10.1063 / 1.4962262$

\section{$2.3 \quad$ Flash Lamp Annealing (FLA)}

The FLA setup used in this work was described by Prucnal et al. [18]. The setup features an RTA system for backside preheating and an FLA system for front-side heating. The RTA system consists of halogen lamps and can reach a maximum temperature of approximately $950^{\circ} \mathrm{C}$ for silicon wafers. The FLA system is equipped with $\mathrm{Xe}$ lamps and can reach temperatures above $1400^{\circ} \mathrm{C}$ for annealing times between 0.8 and $20 \mathrm{~ms}$. A special reflector is mounted above the Xe lamps to ensure a homogeneous temperature distribution across the sample surface. The spectrum of the Xe lamps used for this experiment has its maximum intensity between 400 and $600 \mathrm{~nm}$. FLA was performed under Ar flow and on films on Si substrates only.

The preanneal step was performed at temperatures between 600 and $800^{\circ} \mathrm{C}$ for 2,3 or 4 min. For the subsequent FLA step, flash energies ranging from 34 up to $62 \mathrm{~J} / \mathrm{cm}^{2}$ were applied for $20.0 \mathrm{~ms}$. Because of the short pulse times, direct temperature measurements during the flash are not possible [19], but a change in FLA energy of $7 \mathrm{~J} / \mathrm{cm}^{2}$ corresponds to a change in surface temperature of $\sim 100^{\circ} \mathrm{C}$. 
Published in: Journal of Applied Physics, vol. 120, p. 105103, 2016.

DOI: $10.1063 / 1.4962262$

\subsection{Sample Characterization}

All GIXRD patterns reported in this work were recorded using a Philips X'Pert MRD system equipped with a $\mathrm{CuK}_{\alpha}$ x-ray $(\lambda=0.154 \mathrm{~nm})$ source. A schematic sketch of a GIXRD measurement of a nanocrystalline sample with all relevant angles is depicted in Figure 1 a). The gracing incidence angle $\omega$ was chosen to be
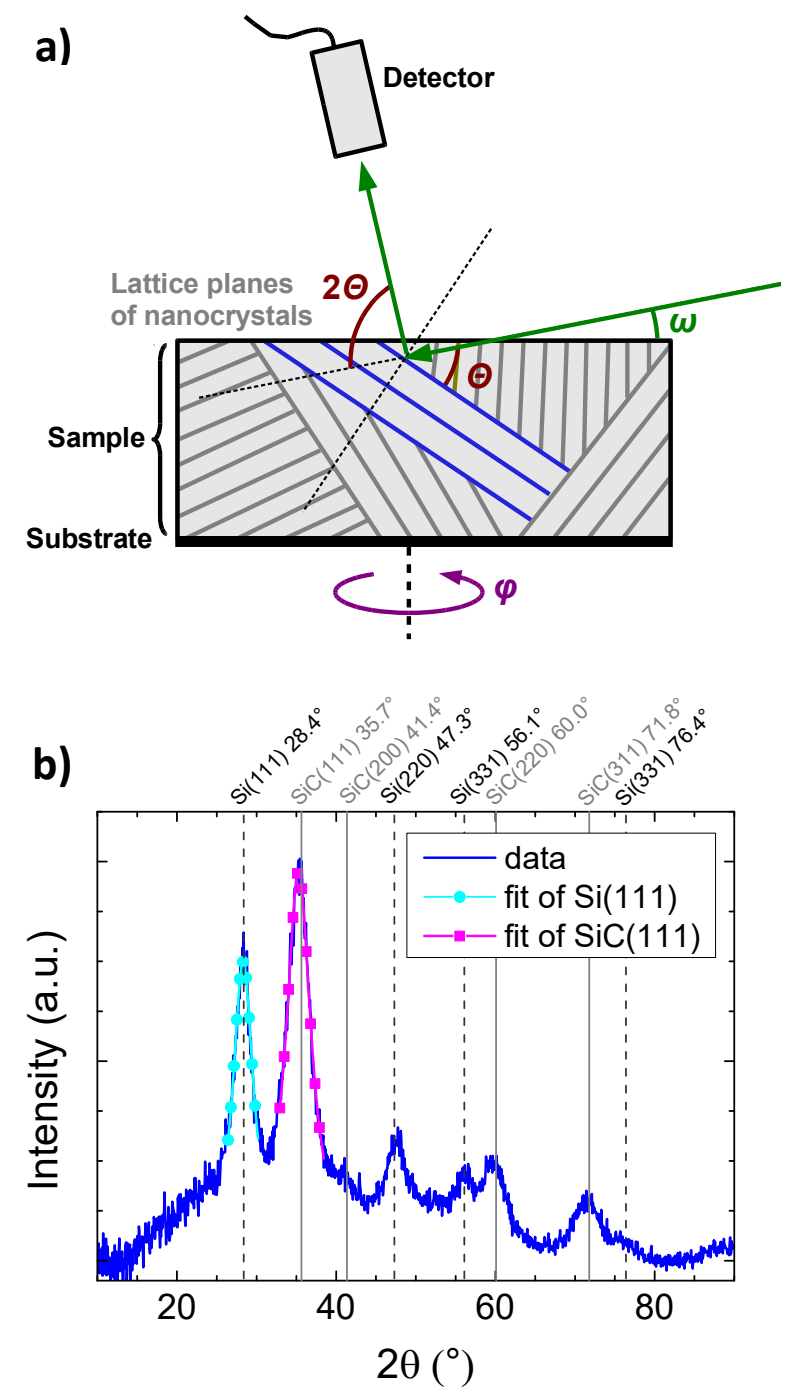

Figure 1: a) Sketch of the beam path of a GIXRD measurement. b) A GIXRD pattern of an annealed $\mathrm{Si}_{0.63} \mathrm{C}_{0.37}$ sample.

$0.3^{\circ}$ for our samples for maximal intensity. The random orientation of the grains in nanocrystalline samples ensures that for all lattice planes $(h k l)$ a group of $\mathrm{NC}$ is oriented to the incident beam such that the Bragg condition is fulfilled. The powder pattern of the samples can be recorded by a $2 \theta$ scan. Such a powder pattern 
Published in: Journal of Applied Physics, vol. 120, p. 105103, 2016.

DOI: $10.1063 / 1.4962262$

of a $\mathrm{Si}_{0.63} \mathrm{C}_{0.37}$ sample is depicted in Figure $1 \mathrm{~b}$ ). The two main peaks ( $\mathrm{Si}(111)$, cyan and $\mathrm{SiC}(111)$ magenta) are fitted to estimate the mean grain size of $\mathrm{Si}$ and $\mathrm{SiC} \mathrm{NC}$ from the FWHM of the fits by the Scherrer equation. Grain size determined by GIXRD always refers to crystalline domain sizes determination without structural defects as twins or stacking faults. For randomly oriented grains, the recorded patterns are independent of the $\varphi$ angle around the normal of the sample surface. The measurement range was chosen to be $10^{\circ} \leq 2 \theta \leq 90^{\circ}$. Additionally, the $\varphi$ angle was varied between $0^{\circ}$ and $360^{\circ}$. The GIXRD analysis is described in greater detail in our previous work $[12,20]$.

FTIR spectroscopy was conducted using a Bruker IFS $113 \mathrm{v}$ instrument over the range of $400 \mathrm{~cm}^{-1}$ to $4000 \mathrm{~cm}^{-1}$ with $6 \mathrm{~cm}^{-1}$ resolution. The two most dominant IR modes in this range are the Si-C stretching

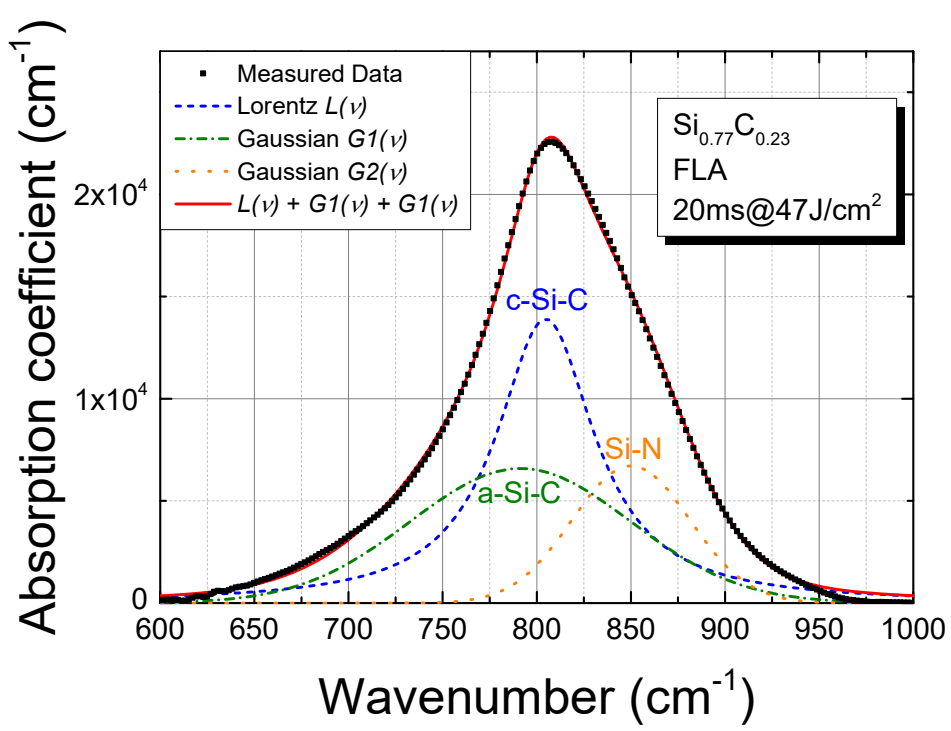

Figure 2: Si-C stretching mode of an exemplary FTIR spectrum fitted with one Lorentzian L(v) and two Gaussian peaks (G1) $(v)$ and $\mathrm{G} 2(v))$. $\mathrm{L}(v)$ represents the crystalline and $\mathrm{G1}(v)$ the amorphous part of the Si-C network, whereas G2(v) is attributed to the asymmetric Si-N stretching vibration.

mode $v_{S i-C}$ around $800 \mathrm{~cm}^{-1}\left([21]\right.$ and references therein) and the $\mathrm{Si}-\mathrm{H}$ stretching mode $v_{S i-H}$ between 2000 and $2200 \mathrm{~cm}^{-1}[22,23]$. The latter allows for the observation of $\mathrm{H}$ effusion during annealing. The former can be used to assess Si-C crystallization by two different methods: The first method is based on the Si-C peak shift to higher wavenumbers with increasing $\mathrm{Si}-\mathrm{C}$ crystallinity and provides qualitative insight into the crystallization process [7]. The second method involves quantifying the Si-C crystalline fraction by fitting the Si-C mode with a Lorentzian L $(v)$ and a Gaussian G1 $(v)$ peak. This fitting is exemplified in Figure 2 for 
Published in: Journal of Applied Physics, vol. 120, p. 105103, 2016.

DOI: $10.1063 / 1.4962262$

a $\mathrm{Si}_{0.77} \mathrm{C}_{0.23}$ layer flashed for $20 \mathrm{~ms}$ at $47 \mathrm{~J} / \mathrm{cm}^{2}$. Because $\mathrm{L}(v)$ represents the crystalline $\mathrm{Si}-\mathrm{C}$ bonds whereas $\mathrm{G}(v)$ corresponds to the amorphous Si-C network, the relation of the peak areas yields an estimate for the Si-C crystalline fraction. This method is widely used in the literature $[6,24,25]$ and was checked for applicability as well as described in detail for our measurements in a previous study [12]. To fit the Si-C mode well, one Lorentzian (L(v)) and two Gaussian peaks (G1(v) and G2(v)) were used. The data treatment is exactly the same as that described in our last paper [12] with one exception: Therein we assigned G2(v) the peak $850 \mathrm{~cm}^{-1}$ to a second amorphous Si-C mode. Further measurements showed an increasing G2(v) mode with increasing temperature, disproving the a-SiC assignment. However, we know from secondary ion mass spectroscopy (SIMS) measurements that there is up to $3 \times 10^{21}$ at $/ \mathrm{cm}^{3}$ nitrogen atoms in our as-dep layers [17]. Therefore, we assign G2(v) to the asymmetric $\mathrm{N}-\mathrm{Si}_{3}$ stretching mode $\left(830-890 \mathrm{~cm}^{-1}[26,27]\right)$ and verify this assignment by estimating the $\mathrm{Si}-\mathrm{N}$ bond density:

$N(\mathrm{Si}-\mathrm{N})=K_{\mathrm{Si}-\mathrm{N}} \int_{v_{1}}^{v_{2}} \frac{\mu(v)}{v} d v \approx \frac{K_{\mathrm{Si}-\mathrm{N}}}{v_{0}} \int_{v_{1}}^{v_{2}} \mu(v) d v[28,29]$.

where $\int_{v_{1}}^{v_{2}} \mu(v) d v$ is the area and $v_{0}$ the central wavenumber of the G2 $(v)$ mode. With $K_{\mathrm{Si}-\mathrm{N}}=2 \times 10^{19} \mathrm{~cm}^{-}$ ${ }^{2}$ [27] and $v_{0}=850 \mathrm{~cm}^{-1}$, we obtain $N(\mathrm{Si}-\mathrm{N})=1.2 \times 10^{22}$ bonds $/ \mathrm{cm}^{3}$ for the G2(v) mode in Figure 2, which corresponds to a nitrogen concentration of $4 \times 10^{21}$ at $/ \mathrm{cm}^{3}$, assuming threefold coordination. This number matches surprisingly well with the SIMS value and supports the assignment of G2(v), which is thus not taken into account for the evaluation of Si-C crystallinity.

SEM images were acquired using a Hitachi SU70 or a Zeiss AURIGA 60 FIB-SEM tool, both equipped with a Schottky emitter, operated at $5 \mathrm{kV}$ accelerating voltage and a working distance of approximately $5 \mathrm{~mm}$.

All ellipsometry data were acquired with a Woollam M-2000 spectroscopic ellipsometer and treated using the software WVASE®. 
Published in: Journal of Applied Physics, vol. 120, p. 105103, 2016.

DOI: $10.1063 / 1.4962262$

III) RESULTS

\subsection{FLA parameter selection}

\subsubsection{Si content}

We found that successful FLA for our samples was only possible for layers with a Si content of $77 \%$ and $63 \%$ but not $50 \%$. The $\mathrm{Si}_{0.50} \mathrm{C}_{0.50}$ FLA samples, which had been treated with a preanneal step of
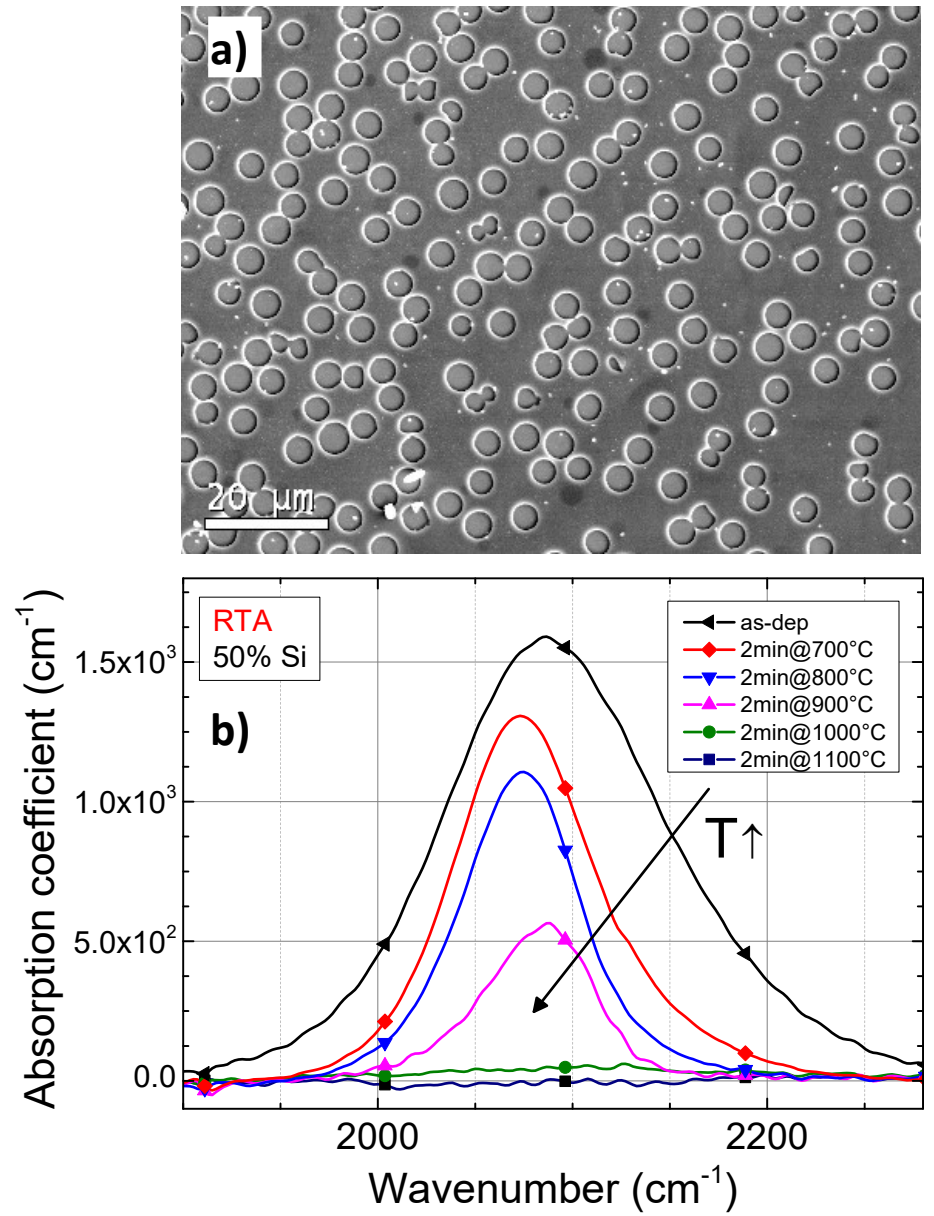

Figure 3: a) SEM image shows strong blistering (circular holes) of a $\mathrm{Si}_{0.50} \mathrm{C}_{0.50}$ film after FLA. b) Development of the FTIR Si-H mode with increasing annealing temperatures for the $\mathrm{Si}_{0.50} \mathrm{C}_{0.50}$ film. The latter shows that $700^{\circ} \mathrm{C}$ is not sufficiently hot for complete $\mathrm{H}$ effusion: After $2 \mathrm{~min} @ 700^{\circ} \mathrm{C}$, there is still a significant $\mathrm{Si}-\mathrm{H}$ peak (red).

$5 \mathrm{~min} @ 700^{\circ} \mathrm{C}$ and flashed with energies between 28 and $47 \mathrm{~J} / \mathrm{cm}^{2}$, all showed a white haze on the surface.

SEM images (see Figure 3 a)) show that the origin of the white haze is strong blistering of the layers originating from the explosive effusion of hydrogen $(\mathrm{H})$ during the flash. Clearly, the preanneal step was not hot and/or long enough for complete $\mathrm{H}$ effusion. This reasoning can be substantiated by the RTA 
Published in: Journal of Applied Physics, vol. 120, p. 105103, 2016.

DOI: $10.1063 / 1.4962262$

treatment of $\mathrm{Si}_{0.50} \mathrm{C}_{0.50}$ samples and by evaluating the corresponding FTIR measurements (Figure $3 \mathrm{~b}$ )). The $\mathrm{Si}-\mathrm{H}$ vibration mode in the range of $2000 \ldots .2200 \mathrm{~cm}^{-1}$ reveals that after $2 \mathrm{~min} @ 900^{\circ} \mathrm{C}$ (magenta) there was still a considerable number of Si-H bonds in the layers. Even after FLA, Si-H bonds were still visible in the FTIR spectra of $\mathrm{Si}_{0.50} \mathrm{C}_{0.50}$ samples (not shown here). Because the hottest and longest preanneal that is possible in the FLA setup is $2 \min @ 800^{\circ} \mathrm{C}$, it was not possible to drive out all the hydrogen before FLA to avoid blistering of the stoichiometric $\mathrm{Si}_{0.50} \mathrm{C}_{0.50}$ samples. Therefore, no further investigation of $\mathrm{Si}_{0.50} \mathrm{C}_{0.50}$ samples was conducted in this work. 
Published in: Journal of Applied Physics, vol. 120, p. 105103, 2016.

DOI: $10.1063 / 1.4962262$

\subsubsection{FLA energy}

A wide range of flash energies were applied to $\mathrm{Si}_{0.63} \mathrm{C}_{0.37}$ and $\mathrm{Si}_{0.77} \mathrm{C}_{0.23}$ films. Because it was not clear what temperatures were achieved at each energy, it was necessary to check whether solid-phase crystallization was in fact taking place or whether some flash energies melted or otherwise damaged the samples. For flash energies above 40 and $47 \mathrm{~J} / \mathrm{cm}^{2}$ for $\mathrm{Si}_{0.63} \mathrm{C}_{0.37}$ and $\mathrm{Si}_{0.77} \mathrm{C}_{0.23}$, respectively, the GIXRD patterns retained their general shape, but the intensities of reflexes appeared to depend on the wafer orientation corresponding to

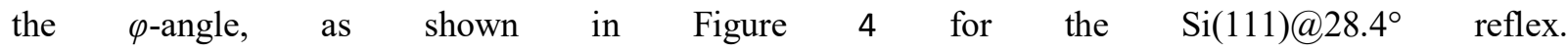

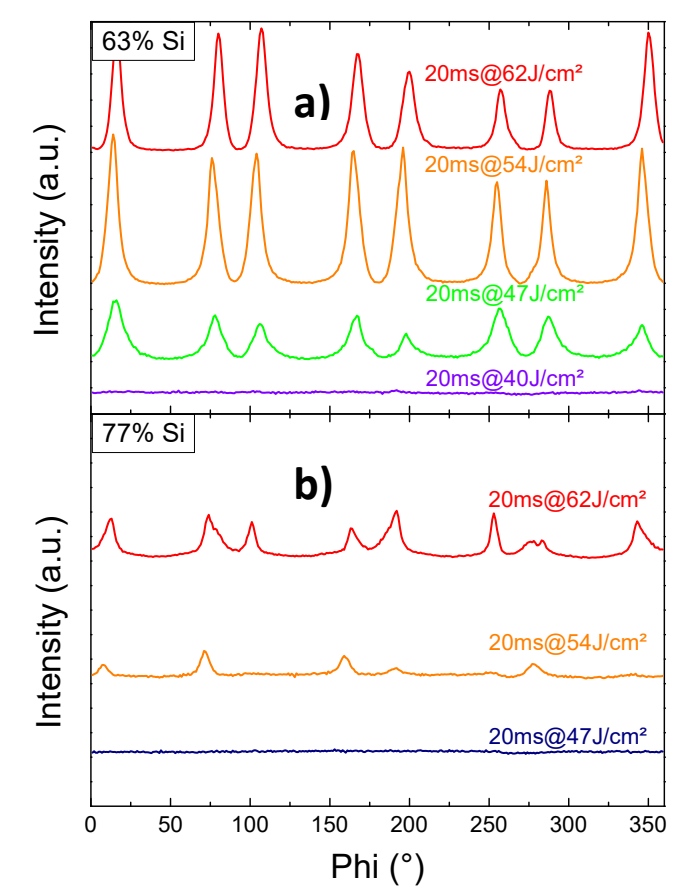

Figure 4: The $\varphi$-orientation dependence of the $\mathrm{Si}(111)$ peak at $2 \theta=28.4^{\circ}$ with increasing FLA energy is shown for $\mathrm{Si}_{0.63} \mathrm{C}_{0.37}$ (a) and $\mathrm{Si}_{0.77} \mathrm{C}_{0.23}$ (b) layers. It is evident that for $\mathrm{Si}_{0.63} \mathrm{C}_{0.37}$ samples, the $\varphi$-dependency starts at lower flash energies and is stronger than for $\mathrm{Si}_{0.77} \mathrm{C}_{0.23}$ samples.

$\mathrm{Si}_{0.63} \mathrm{C}_{0.37}$ films (Figure $4 \mathrm{a}$ )) showed 4-fold symmetry, each with two peaks, which increased in intensity for $54 \mathrm{~J} / \mathrm{cm}^{2}$ and decreased slightly in intensity for $62 \mathrm{~J} / \mathrm{cm}^{2}$. In $\mathrm{Si}_{0.77} \mathrm{C}_{0.23}$ layers (Figure $4 \mathrm{~b}$ )), the $\varphi$ dependence only began at $54 \mathrm{~J} / \mathrm{cm}^{2}$ and increased for $62 \mathrm{~J} / \mathrm{cm}^{2}$. In contrast, the intensity of the $\mathrm{SiC}$ reflexes showed no dependence on sample orientation in either sample. Thus, at a certain flash energy the orientation of the Si NC was no longer randomly distributed, whereas the $\mathrm{SiC}$ grain orientation remained random for 
Published in: Journal of Applied Physics, vol. 120, p. 105103, 2016.

DOI: $10.1063 / 1.4962262$

all energies. The evaluation of $\mathrm{Si}$ and $\mathrm{SiC}$ grain sizes from GIXRD spectra acquired at different sample orientations shows that an increase in $\operatorname{Si}(111)$ peak intensity at a given orientation is correlated with an increase in Si NC diameter in that particular direction. This behavior is not surprising because the GIXRD intensity is in general positively correlated with the number of scattering centers [30] and hence with the size of crystalline clusters. This relationship is illustrated in Figure 5 a) for $\mathrm{Si}_{0.63} \mathrm{C}_{0.37}$ and in Figure 5 b) for $\mathrm{Si}_{0.77} \mathrm{C}_{0.23}$. The connected data points represent the GIXRD measurements in the

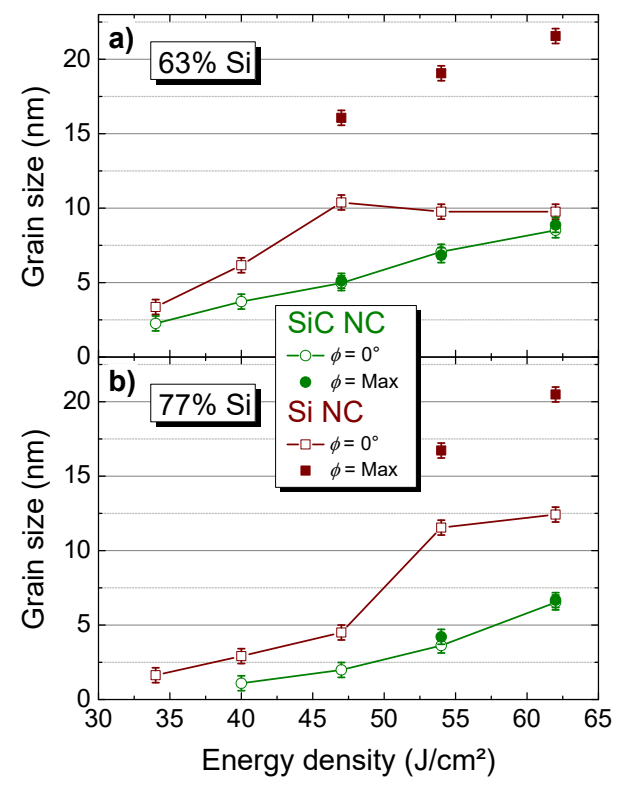

Figure 5: SiC (green circles) and Si (brown squares) grain sizes estimated from the $\mathrm{Si}(111)$ and $\mathrm{SiC}(111)$ reflex at $2 \vartheta=28.4^{\circ}$ and at $2 \vartheta=31.7^{\circ}$, respectively for $\mathrm{Si}_{0.63} \mathrm{C}_{0.37}(\mathrm{a})$ and $\mathrm{Si}_{0.77} \mathrm{C}_{0.23}(\mathrm{~b})$. The straight lines connect the data points of measurements performed in the standard sample orientation referred to as $\varphi=0^{\circ}$. The additional grain sizes at high energies were calculated from diffraction patterns taken at $\varphi$-angles of maximal intensity of the Si(111) reflex at $28.4^{\circ}$. The $\mathrm{Si}$ NC size is a function of both, the flash energy and the sample orientation. The SiC NC size remains independent of the sample orientation even for high flash energies, but a large difference between the $\mathrm{Si}_{0.63} \mathrm{C}_{0.37}$ and $\mathrm{Si}_{0.77} \mathrm{C}_{0.23}$ samples can be observed.

standard sample orientation, referred to as $\varphi=0^{\circ}$, whereas the additional grain sizes (filled symbols) correspond to the spectra captured at the maximal intensity of the Si(111)@28.4 reflex. The largest variation in Si NC grain size (brown squares) was observed for $63 \% \mathrm{Si}$ samples flashed for $20 \mathrm{~ms}$ at $62 \mathrm{~J} / \mathrm{cm}^{2}$ and ranged from $(9.8 \pm 0.5) \mathrm{nm}$ to $(21.6 \pm 0.5) \mathrm{nm}$. The $\mathrm{SiC} \mathrm{NC}$ grain size (green circles) did not depend on sample orientation and increased continuously with the flash energy for layers with Si contents of $63 \%$ and 77\%. The $\varphi$-dependence of the Si grain size and the very large NC suggest that at high energies, a different crystallization mechanism takes place, perhaps via the Si liquid phase $\left(T_{\mathrm{m}}(\mathrm{Si})=1414^{\circ} \mathrm{C}[31]\right)$. As our aim 
Published in: Journal of Applied Physics, vol. 120, p. 105103, 2016.

DOI: $10.1063 / 1.4962262$

is the solid-phase crystallization of Si NC, we forgo further investigation of the high-energy FLA samples.

In the following, we consider only samples with orientation-independent GIXRD spectra and establish a maximal suitable FLA energy of $47 \mathrm{~J} / \mathrm{cm}^{2}$ for $\mathrm{Si}_{0.77} \mathrm{C}_{0.23}$ and $40 \mathrm{~J} / \mathrm{cm}^{2}$ for $\mathrm{Si}_{0.63} \mathrm{C}_{0.37}$.

\subsection{Formation of nanocrystals by RTA and FLA}

\subsubsection{GIXRD}

The nanostructure of samples annealed by RTA and FLA under conditions suitable for solid-phase crystallization was studied by GIXRD.

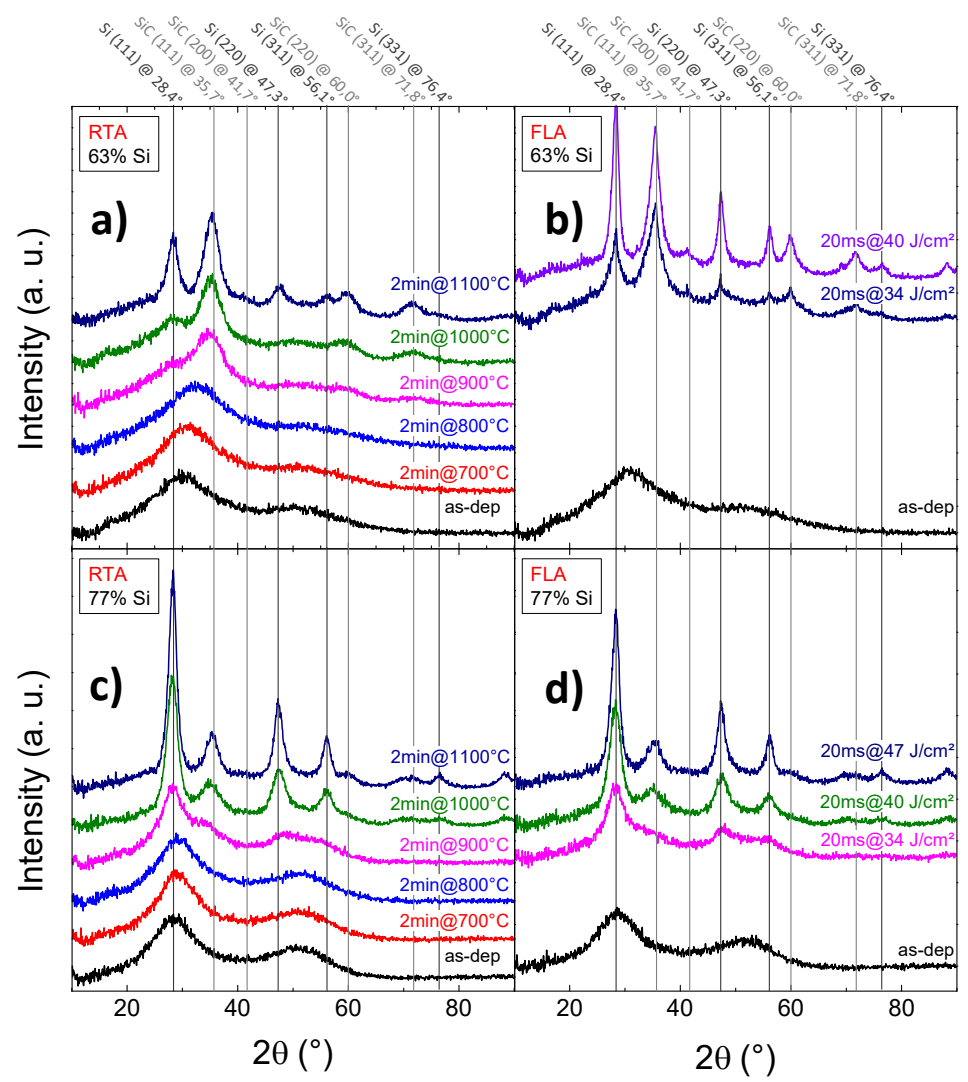

Figure 6: GIXRD patterns of RTA (a) and c)) and FLA (b) and d)) samples with a Si content of $63 \%$ (a) and b)) and $77 \%$ (c) and d)). To compare flash energies and annealing temperatures, the GIXRD patterns of FLA samples were plotted in line with GIXRD patterns of RTA samples with a similar shape. 
Published in: Journal of Applied Physics, vol. 120, p. 105103, 2016.

DOI: $10.1063 / 1.4962262$

As previously mentioned, the FLA process is characterized by the flash energy and not by the sample temperature. To compare the FLA results with the results obtained from RTA-processed samples, we gathered GIXRD results based on RTA temperature data and plotted the GIXRD results based on FLA energy data in line with the RTA data they most resemble. The final results are presented in Figure 6. All FLA samples were subjected to a preanneal step of either $2 \min @ 800^{\circ} \mathrm{C}(63 \% \mathrm{Si}$ content, Figure $\left.6 \mathrm{~b})\right)$ or

\section{Energy $\left(\mathrm{J} / \mathrm{cm}^{2}\right)$}

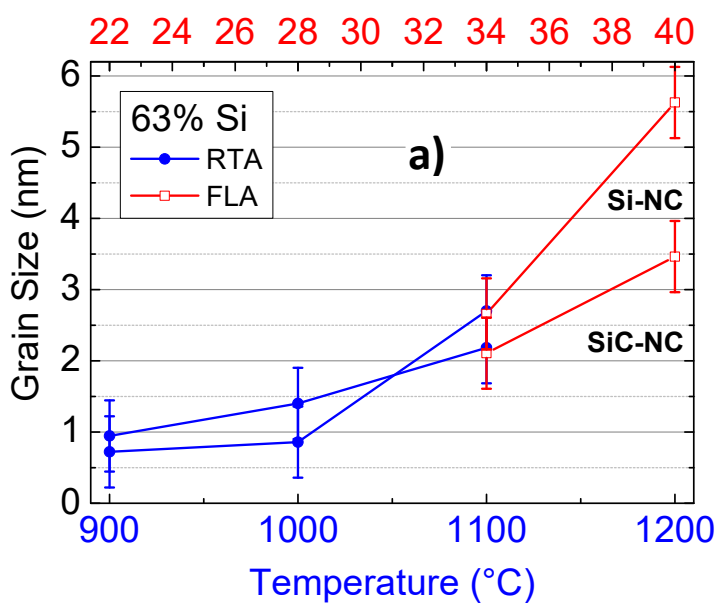

Energy $\left(\mathrm{J} / \mathrm{cm}^{2}\right)$

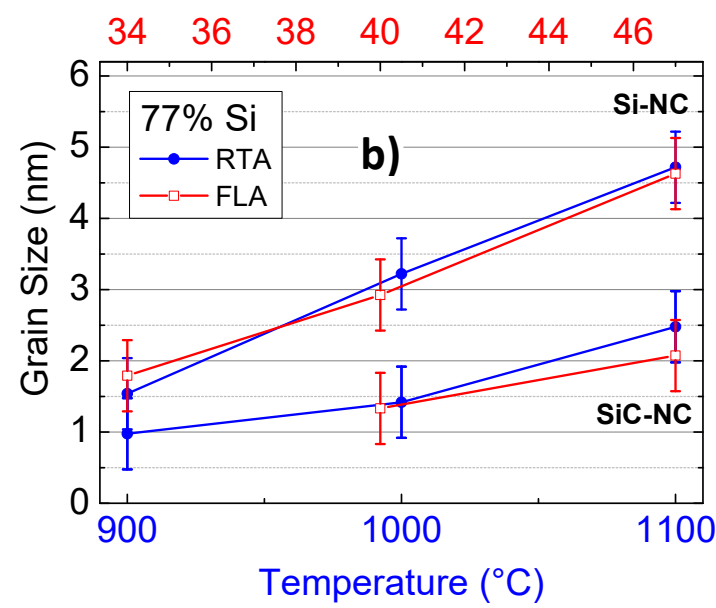

Figure 7: Grain sizes calculated from the GIXRD patterns in Figure 6 for $\mathrm{Si}_{0.63} \mathrm{C}_{0.37}(\mathrm{a})$ and $\mathrm{Si}_{0.77} \mathrm{C}_{0.23}$ (b). The correspondence between RTA temperatures and FLA energies is the same as that in Figure 6. Si NC size is observed to be a function of both Si content and annealing temperature, whereas SiC NC size is independent of film composition and depends on annealing temperature and the corresponding flash energy.

$4 \min @ 700^{\circ} \mathrm{C}(77 \% \mathrm{Si}$ content, Figure $\left.6 \mathrm{~d})\right)$ before FLA. At a Si content of 63\%, the highest RTA temperature of $1100^{\circ} \mathrm{C}$ yielded data similar to that obtained at the lowest FLA energy of $34 \mathrm{~J} / \mathrm{cm}^{2}$. The situation was different for a $\mathrm{Si}$ content of $77 \%$, at which a flash energy of $34 \mathrm{~J} / \mathrm{cm}^{2}$ produced a GIXRD pattern similar to that observed for RTA at $900^{\circ} \mathrm{C}$. The data obtained from $\mathrm{Si}_{0.77} \mathrm{C}_{0.23}$ samples exposed to FLA at 40 and $47 \mathrm{~J} / \mathrm{cm}^{2}$ can be compared with those obtained from films that underwent RTA at 1000 and $1100^{\circ} \mathrm{C}$, respectively. The average grain sizes of $\mathrm{Si}$ and $\mathrm{SiC} \mathrm{NC}$ were calculated from the GIXRD spectra and are plotted as a function of the RTA temperature and the FLA energy in Figure 7. Therein, the attribution of the flash energies to a certain RTA temperature corresponds to the attribution of the spectra in Figure 6. The results confirm our assumption regarding the GIXRD spectra: In the $\mathrm{Si}_{0.63} \mathrm{C}_{0.37}$ samples (Figure $7 \mathrm{a}$ )), the hottest RTA temperature of $1100^{\circ} \mathrm{C}$ led to the same $\mathrm{NC}$ grain sizes (approximately 2.2 and $2.6 \mathrm{~nm}$ for 
Published in: Journal of Applied Physics, vol. 120, p. 105103, 2016.

DOI: $10.1063 / 1.4962262$

$\mathrm{SiC}$ and $\mathrm{Si} \mathrm{NC}$, respectively) produced by FLA at the lowest energy of $34 \mathrm{~J} / \mathrm{cm}^{2}$. For higher flash energies, the grains continued to grow to $3.5 \pm 0.5 \mathrm{~nm}$ in diameter for $\mathrm{SiC} \mathrm{NC}$ and $5.6 \pm 0.5 \mathrm{~nm}$ for $\mathrm{Si} \mathrm{NC}$, larger than all Si NC we ever produced in these films with RTA or a furnace anneal in prior studies $[12,20]$. The grain sizes in the $\mathrm{Si}_{0.77} \mathrm{C}_{0.23}$ samples (Figure $7 \mathrm{~b}$ )) confirm that the flash with $34 \mathrm{~J} / \mathrm{cm}^{2}$ led to NC comparable to those formed by RTA at $900^{\circ} \mathrm{C}$ and the increase to $47 \mathrm{~J} / \mathrm{cm}^{2}$ corresponds to an increase in temperature to $1100^{\circ} \mathrm{C}$. The results also confirm findings reported in our previous work [12], which showed that the Si NC size is a function of the Si content in samples whereas the SiC NC size depends only on the annealing temperature. The FLA energy that evokes the same Si NC sizes as RTA at a certain temperature increases with Si content. For example, Figure 6 and Figure 7 show that $34 \mathrm{~J} / \mathrm{cm}^{2}$ produced larger $\mathrm{NC}$ in $\mathrm{Si}_{0.63} \mathrm{C}_{0.37}$ than in $\mathrm{Si}_{0.77} \mathrm{C}_{0.23}$, which means that the crystallization process during FLA is favored in films containing less Si. This reasoning is counterintuitive because Si crystallization would be expected to be easier if more $\mathrm{Si}$ is present. The same trend was observed for FLA at higher energies, as will be discussed in greater detail in the discussion section. 
Published in: Journal of Applied Physics, vol. 120, p. 105103, 2016.

DOI: $10.1063 / 1.4962262$

\subsubsection{FTIR}

Figure 8 shows the FTIR spectra of all $\mathrm{Si}_{0.77} \mathrm{C}_{0.23}$ and $\mathrm{Si}_{0.63} \mathrm{C}_{0.37}$ samples on $\mathrm{Si}$ substrates treated by RTA (Figure 8 a) and c)) and low-energy FLA (Figure 8 b) and d)). The dominant Si-C stretching vibration around $800 \mathrm{~cm}^{-1}$ is depicted in the main panels, whereas the insets show the $\mathrm{Si}-\mathrm{H}$ stretching vibration at approximately $2000 \mathrm{~cm}^{-1}$. It is important to note that neither for RTA nor for FLA could the formation of Si-O bonds be observed because no peak around $1000 \mathrm{~cm}^{-1}$ appeared at higher temperatures.

The area of the Si-C mode increased and the peaks shifted to higher wavenumbers as the annealing
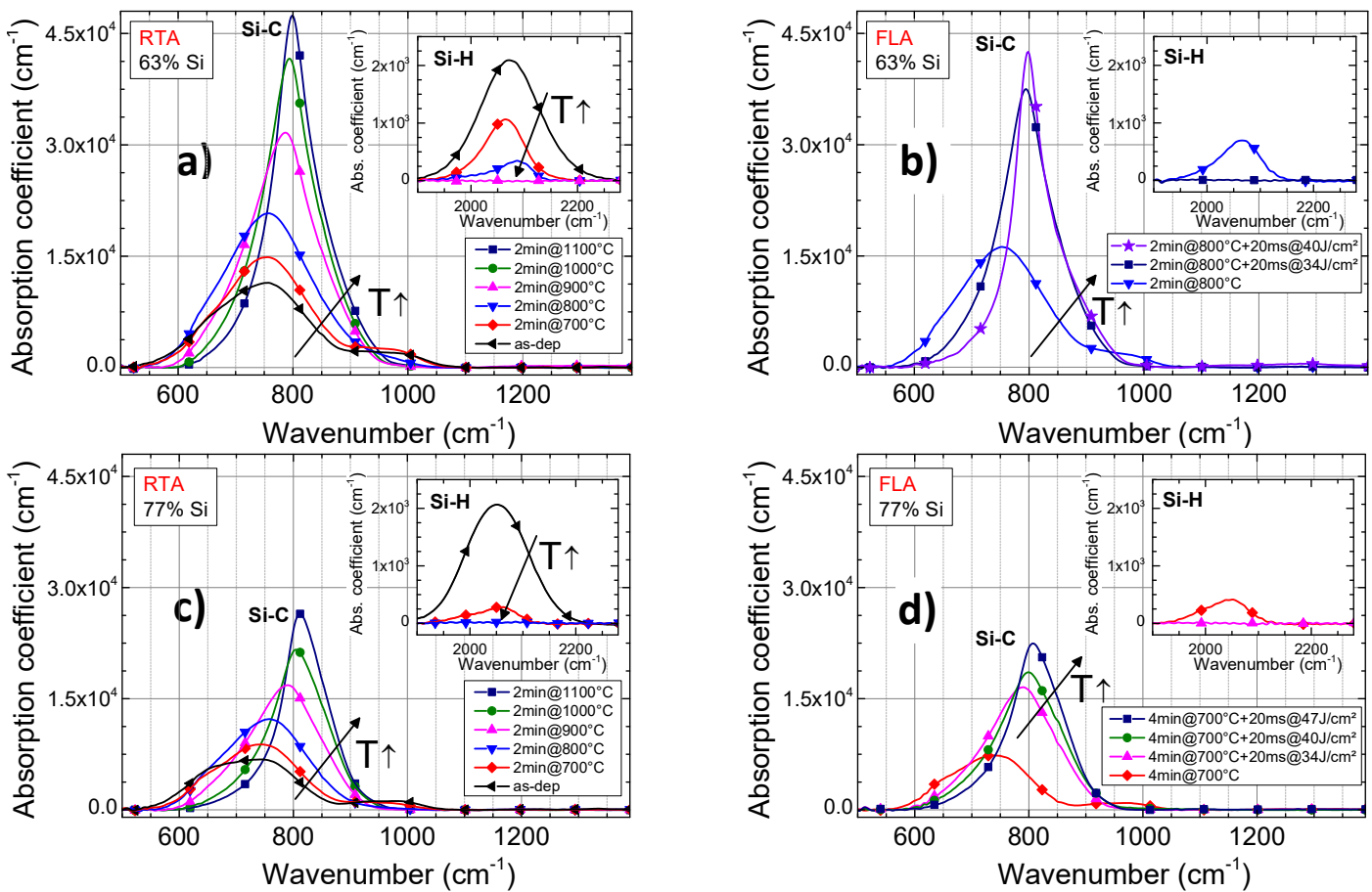

Figure 8: FTIR spectra of RTA (a) and (c) and FLA (b) and (d) samples with a Si contents of 63\% (a) and (b) and 77\% (c) and (d). Whereas the Si-C mode increases with temperature und flash energy, the $\mathrm{Si}-\mathrm{H}$ vibration depicted in the insets decreases.

temperatures as well as the flash energies increased. The latter is associated with the $\mathrm{SiC}$ crystallization process, whereas the former corresponds to a growing $\mathrm{Si}-\mathrm{C}$ bond density in the samples. As expected based on the film composition, the $\mathrm{Si}_{0.77} \mathrm{C}_{0.23}$ samples showed smaller peak areas and hence lower $\mathrm{Si}-\mathrm{C}$ bond densities than the $\mathrm{Si}_{0.63} \mathrm{C}_{0.37}$ samples under comparable annealing conditions. Another difference caused by the Si content was the temperature of complete $\mathrm{H}$ effusion $T_{\text {out }}$. Comparing the insets of Figure 8 a) and c) reveals that $T_{\text {out }} \geq 800^{\circ} \mathrm{C}$ in the $\mathrm{Si}_{0.77} \mathrm{C}_{0.23}$ samples, whereas for the $\mathrm{Si}_{0.63} \mathrm{C}_{0.37}$ samples $T_{\text {out }} \geq 900^{\circ} \mathrm{C}$. As mentioned previously (Figure $3 \mathrm{~b}$ )), $T_{\text {out }} \sim 900^{\circ} \mathrm{C}$ in $\mathrm{Si}_{0.50} \mathrm{C}_{0.50}$ RTA samples. This trend appears to be the 
Published in: Journal of Applied Physics, vol. 120, p. 105103, 2016.

DOI: $10.1063 / 1.4962262$

same for FLA; indeed, the insets of Figure $8 \mathrm{~b}$ ) and d) show that the area of the Si-H mode was larger for $\mathrm{Si}_{0.63} \mathrm{C}_{0.37}$ preannealed at $800^{\circ} \mathrm{C}$ than for $\mathrm{Si}_{0.77} \mathrm{C}_{0.23}$ preannealed at $700^{\circ} \mathrm{C}$. As discussed in section 3.1, no suitable $\mathrm{Si}_{0.50} \mathrm{C}_{0.50}$ FLA samples exist. The dependence of $T_{\text {out }}$ on $\mathrm{Si}$ content can be explained by the differences in back-bonding. With increasing Si content, the nearest neighbors of $\mathrm{Si}$ atoms to which $\mathrm{H}$ is bonded are increasingly other $\mathrm{Si}$ atoms, not $\mathrm{C}$ atoms. Because $\mathrm{Si}$ atoms show a lower electronegativity than $\mathrm{C}$ atoms, the $\mathrm{H}$ atoms are less strongly bonded with increasing $\mathrm{Si}$ content and can effuse at lower temperatures $[32,33]$. This explanation is supported by the fact that the $\mathrm{Si}-\mathrm{H}_{n}$ mode in as-dep samples shifts to lower wavenumbers with increasing Si content (see Figure $3 \mathrm{~b}$ ) and inset of Figure 8 a) and c)), which corresponds to a weakening of the corresponding bond.

The contribution of $\mathrm{H}$ from $\mathrm{C}-\mathrm{H}$ bonds to $\mathrm{H}$ effusion could not be examined in this work because the $\mathrm{C}-\mathrm{H}$ FTIR bonds were too weak to analyze.

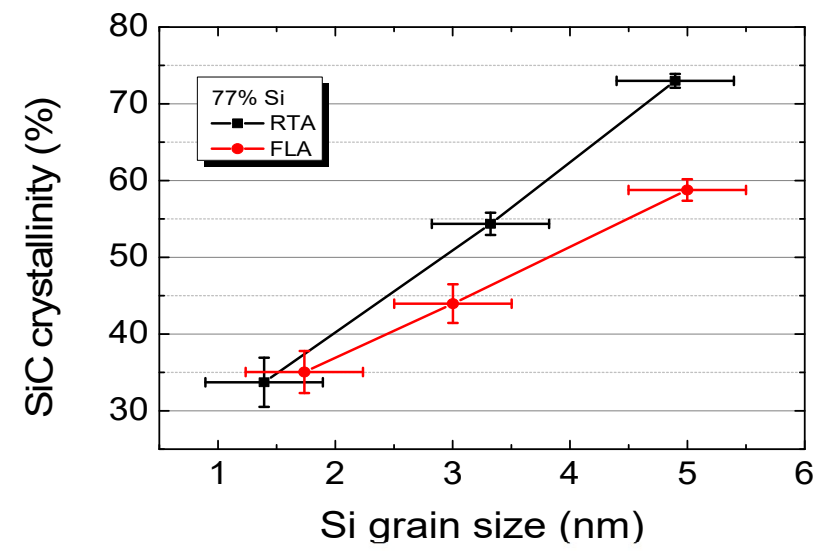

Figure 9: The SiC crystallinity determined from FTIR spectra as a function of the Si NC size derived from GIXRD patterns show that FLA leads to less SiC crystallinity than RTA for a given Si NC size.

Whereas the overall trends in FTIR spectra of FLA and RTA samples are similar, a careful analysis (described in Section 2.4) of the $\mathrm{SiC}$ crystallization in $\mathrm{Si}_{0.77} \mathrm{C}_{0.23}$ samples reveals a slight difference, as depicted in Figure 9. For Si grain sizes larger than $2 \mathrm{~nm}$ (as determined by GIXRD), we observed significantly lower SiC crystallinity in FLA samples compared with that observed in RTA samples for a given Si grain size. The difference in SiC crystallinity increased with increasing Si NC size. This trend will be discussed in the next section.

IV) DISCUSSION 
Published in: Journal of Applied Physics, vol. 120, p. 105103, 2016.

DOI: $10.1063 / 1.4962262$

\subsection{Reduced SiC crystallinity in FLA samples}

Figure 9 shows a decrease in SiC crystallinity in FLA samples relative to that of RTA samples for the same $\mathrm{Si}$ NC size. This result is remarkable because a reduction in $\mathrm{SiC}$ crystallinity promises a defect reduction in samples [8]. Because Figure 7 b) shows that $\mathrm{SiC} \mathrm{NC} \mathrm{size} \mathrm{remained} \mathrm{the} \mathrm{same} \mathrm{within} \mathrm{experimental} \mathrm{error} \mathrm{for}$ a given Si NC size, irrespective of whether FLA or RTA was used, the reduced SiC crystallinity for FLA must have resulted from a lower number of SiC NC in FLA compared with that in RTA. This finding can be explained with the help of classical crystallization theory in terms of nucleation and crystal growth. Theory states that the temperature $T_{\mathrm{N}}$ at which maximal nucleation takes place is lower than the temperature of maximum crystal growth $T_{\mathrm{G}}$ [34]. Near the phase transition temperature $T_{\mathrm{T}}$, which is the melting point for $\mathrm{Si}\left(T_{\mathrm{T}}^{\mathrm{Si}}=1414^{\circ} \mathrm{C}[31]\right)$ and the decomposition point for $\mathrm{SiC}\left(T_{\mathrm{T}}^{\mathrm{SiC}}>2300^{\circ} \mathrm{C}\right)$, there is rapid crystal growth but a marginal nucleation rate. The RTA samples shown in Figure 9 were annealed between $900^{\circ} \mathrm{C}$ and $1100^{\circ} \mathrm{C}$, and the FLA samples were exposed to comparable annealing conditions, as demonstrated by the consistency of the structural measurements shown in Figure 6 and Figure 8. Thus, in RTA and FLA, $\mathrm{T}<<T_{\mathrm{T}}^{\mathrm{SiC}}$ such that both nucleation and growth of SiC NC occur throughout the RTA and FLA processes. The larger number of SiC NC in RTA samples may therefore be due to a longer plateau time or a longer heating ramp. The plateau time was $20 \mathrm{~ms}$ for FLA and $2 \mathrm{~min}$ for RTA, and the ramp-up time was $22 \mathrm{~s}$ for RTA at $1100^{\circ} \mathrm{C}$. In the case of FLA, the heating of the samples was limited only by the thermal properties of the layer. The thermal diffusion length $L_{\mathrm{D}}$ is the penetration depth of heat into a material with thermal diffusivity $\alpha$ during a pulse duration $t$ :

$$
L_{\mathrm{D}}=\sqrt{\alpha t}
$$

The thermal diffusivity is given by

$$
\alpha=\frac{k}{\delta c_{p}}
$$

The other parameters are the thermal conductivity $k$, the density of the material $\delta$ and the specific heat capacity $c_{\mathrm{p}}$ : 
Published in: Journal of Applied Physics, vol. 120, p. 105103, 2016.

DOI: $10.1063 / 1.4962262$

Table 1: Literature values for the determination of the thermal diffusivity $\alpha$ and the thermal diffusion length $L_{D}$ in Si and SiC.

\begin{tabular}{|c|c|c|c|c|c|c|c|c|}
\hline Material & $T$ & $\begin{array}{l}k \\
(\mathbf{W} / \mathbf{c m ~ K})\end{array}$ & $\begin{array}{l}c_{\mathrm{p}} \\
(\mathrm{J} / \mathrm{g} \mathrm{K})\end{array}$ & $\begin{array}{l}\delta \\
\left(\mathrm{g} / \mathrm{cm}^{3}\right)\end{array}$ & Ref. & $\begin{array}{l}\alpha=k /\left(\delta \cdot c_{\mathrm{p}}\right) \\
\left(\mathrm{cm}^{2} / \mathrm{s}\right)\end{array}$ & $\begin{array}{l}\boldsymbol{L}_{\mathbf{D}}=\sqrt{\boldsymbol{\alpha} t} \\
(\boldsymbol{\mu m}) \\
\text { for } t=20 \mathrm{~ms}\end{array}$ & $\begin{array}{l}\boldsymbol{t}=\boldsymbol{L}_{\mathbf{D}^{2}} / \boldsymbol{\alpha} \\
(\mathbf{m s}) \\
\text { for } L_{\mathrm{D}}=200 \mathrm{~nm}\end{array}$ \\
\hline \multirow[t]{3}{*}{$\mathbf{a - S i}$} & $27^{\circ} \mathrm{C}$ & 0.007 & 0.77 & 2.30 & [35] & 0.0040 & 89 & 0.1012 \\
\hline & $1000^{\circ} \mathrm{C}$ & 0.011 & 1.07 & 2.30 & [35] & 0.0045 & 95 & 0.0895 \\
\hline & $1145^{\circ} \mathrm{C}$ & 0.013 & 1.12 & 2.30 & [35] & 0.0050 & 100 & 0.0793 \\
\hline poly-Si & $27^{\circ} \mathrm{C}$ & 0.16 & as c-Si & as c-Si & [36] & $0.1[36]$ & & \\
\hline \multirow[t]{3}{*}{ c-Si } & $27^{\circ} \mathrm{C}$ & 1.56 & 0.71 & 2.33 & [35] & 0.9430 & 1373 & 0.0004 \\
\hline & $1000^{\circ} \mathrm{C}$ & 0.25 & 0.96 & 2.30 & [35] & 0.1132 & 476 & 0.0035 \\
\hline & $1414^{\circ} \mathrm{C}$ & 0.22 & 1.03 & 2.29 & [35] & 0.0933 & 432 & 0.0043 \\
\hline a-SiC:H & $27^{\circ} \mathrm{C}$ & & & $\begin{array}{l}1.51-2.1 \\
5\end{array}$ & [37] & & & \\
\hline a-SiC & $27^{\circ} \mathrm{C}$ & $1.3-1.6$ & & & [38] & & & \\
\hline \multirow{3}{*}{$\begin{array}{l}\text { poly-SiC } \\
\text { (with } \\
\text { additives) }\end{array}$} & $27^{\circ} \mathrm{C}$ & 0.48 & 0.7 & & [39] & & & \\
\hline & $1000^{\circ} \mathrm{C}$ & 0.27 & $1.2^{*}$ & & [39] & & & \\
\hline & $1500^{\circ} \mathrm{C}$ & $0.18^{*}$ & & & [39] & & & \\
\hline \multirow[t]{4}{*}{ c-SiC } & $27^{\circ} \mathrm{C}$ & 4.9 & 0.85 & $3.217^{*}$ & {$[40,41]$} & & & \\
\hline & $130^{\circ} \mathrm{C}$ & & 1.04 & & [42] & & & \\
\hline & $330^{\circ} \mathrm{C}$ & & 1.20 & & [42] & & & \\
\hline & $730^{\circ} \mathrm{C}$ & & & & [42] & & & \\
\hline
\end{tabular}

$\overline{\text { For our } \mathrm{Si}_{x} \mathrm{C}_{1-x} \text { layers, these values are not known, but we can estimate } \alpha \text { based on values reported for a-Si }}$

and $\mathrm{SiC}$ in the literature, as summarized in Table 1. For a-SiC:H, there is no complete dataset available, but a lower bound on its thermal diffusivity $\alpha_{\text {Sic }}^{\min }$ can be estimated based on the values marked with a * in Table 1. The resulting $\alpha_{S i C}^{\min }$ of $0.0047 \mathrm{~cm}^{2} / \mathrm{s}$ is higher than $\alpha_{a-S i}^{1000^{\circ} \mathrm{C}}=0.0045 \mathrm{~cm}^{2} / \mathrm{s}$. Therefore, we can use $\alpha_{a-S i}^{1000^{\circ} \mathrm{C}}$ for a lower limit of the thermal diffusivity in the $\mathrm{Si}_{x} \mathrm{C}_{1-x}$ layers, which indicates that the heating time in FLA is less than $0.1 \mathrm{~ms}$ and therefore five orders of magnitude shorter than in the case of RTA. Consequently, compared with RTA, the FLA process leads to the formation of fewer SiC grains during ramping-up and during the temperature plateau. 
Published in: Journal of Applied Physics, vol. 120, p. 105103, 2016.

DOI: $10.1063 / 1.4962262$

\subsection{Influence of Si-content on crystallization behavior:}

As shown in Figure 6 and Figure 5, a certain FLA energy leads to the formation of larger Si and SiC NC in $\mathrm{Si}_{0.63} \mathrm{C}_{0.37}$ than in $\mathrm{Si}_{0.77} \mathrm{C}_{0.23}$ layers. Possible explanations include (i) better absorption in the $\mathrm{Si}_{0.63} \mathrm{C}_{0.37}$ than in the $\mathrm{Si}_{0.77} \mathrm{C}_{0.23}$ layers (although this would be counterintuitive); (ii) a strong effect of the preanneal step, which was $2 \mathrm{~min} @ 800^{\circ} \mathrm{C}$ for $\mathrm{Si}_{0.63} \mathrm{C}_{0.37}$ and $4 \mathrm{~min} @ 700^{\circ} \mathrm{C}$ for $\mathrm{Si}_{0.77} \mathrm{C}_{0.23}$ samples; and (iii) the effect of the amount of hydrogen remaining after the preanneal step, which depends on the Si content. Each possibility is examined in turn.

(i): We verified the absorption of the samples by modeling $A_{\mathrm{L}-\mathrm{i}}(\lambda)=1-R_{\mathrm{i}}(\lambda)-T_{\mathrm{i}}(\lambda)(\mathrm{i}=63,77)$ based on the dielectric function $\varepsilon_{i}(E)$ for preannealed $\mathrm{Si}_{0.63} \mathrm{C}_{0.37}$ and $\mathrm{Si}_{0.77} \mathrm{C}_{0.23}$ layers on $\mathrm{Si}$ substrate. $\varepsilon_{\mathrm{i}}(E)$ were obtained

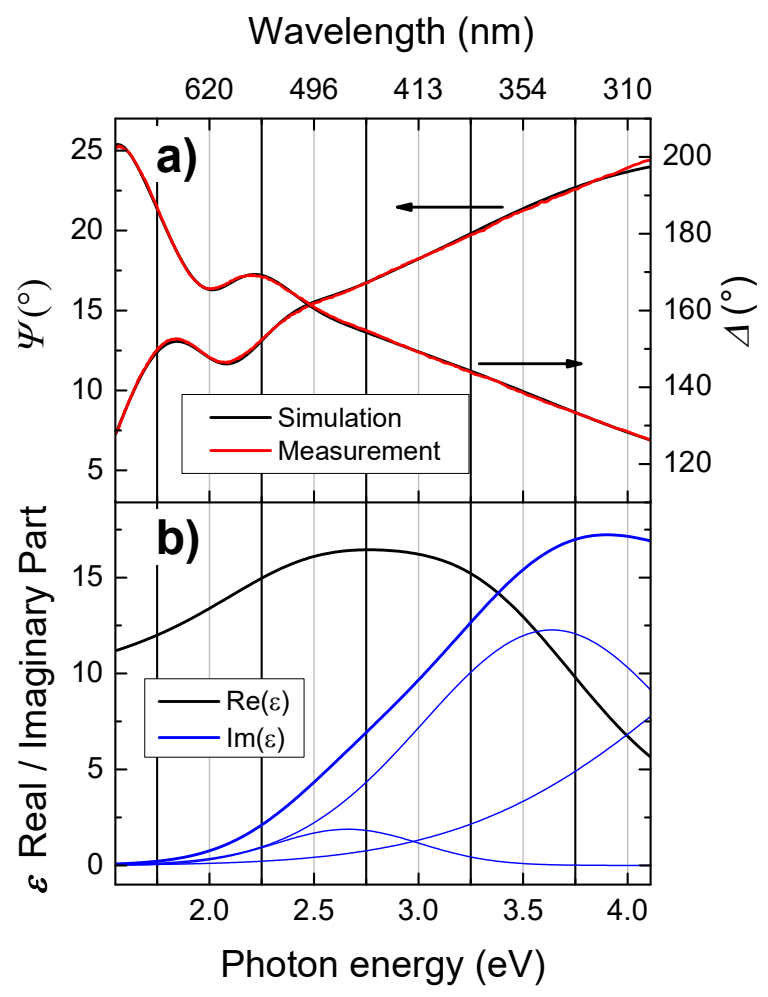

Figure 10: a) Ellipsometry data (red) and simulation (black) of a- $\mathrm{Si}_{0.77} \mathrm{C}_{0.23}: \mathrm{H}$ sample. b) Simulated imaginary part of the dielectric function $\varepsilon(E)$ (blue, thick) with three Gaussian contributions (blue, thin) and real part (black) derived by KramersKronig relation.

via spectroscopic ellipsometry. The simulation based data analysis was performed within the software WVASE ${ }^{\circledR}$ employing a parametric model of 3 oscillators, each contributing a Gaussian profile to the imaginary part of the dielectric function: 
Published in: Journal of Applied Physics, vol. 120, p. 105103, 2016.

DOI: $10.1063 / 1.4962262$

$$
\varepsilon_{\mathrm{G}}(E)=A \exp \left(\frac{\left(E-E_{0}\right)^{2}}{4 \ln 2 \sigma^{2}}\right)
$$

with $A$ being the dimensionless amplitude, $E_{0}$ the position of the Gauss peak and $\sigma$ the full width at half maximum. The contribution to the dielectric function real part is internally calculated via Kramers-Kronig relations. In Figure 10, the simulated and measured $\Psi$ and $\Delta$ spectra (Figure 10 a)), as well as the dielectric function results (Figure 10 b)) with the individual Gaussian contributions (lighter blue lines) are shown for the a-Si ${ }_{0.77} \mathrm{C}_{0.23}: \mathrm{H}$ sample. Results obtained with a Tauc-Lorentz model [43] were found to produce the same characteristic run of the dielectric function. However, in the low energy regime this model provided insufficient flexibility. These dielectric functions were then used to simulate $R_{\mathrm{i}}(\lambda)$ and $T_{\mathrm{i}}(\lambda)$ and thereby $A_{\mathrm{L}}$ i $(\lambda)$ with the help of the software CODE. Figure 11 a) shows the calculated absorption $A_{\mathrm{L}-\mathrm{i}}(\lambda)$ for $\mathrm{Si}_{0.63} \mathrm{C}_{0.37}$ (blue) and $\mathrm{Si}_{0.77} \mathrm{C}_{0.23}$ (green) (left-hand ordinate) with the normalized intensity of the FLA Xe lamps $I(\lambda)$

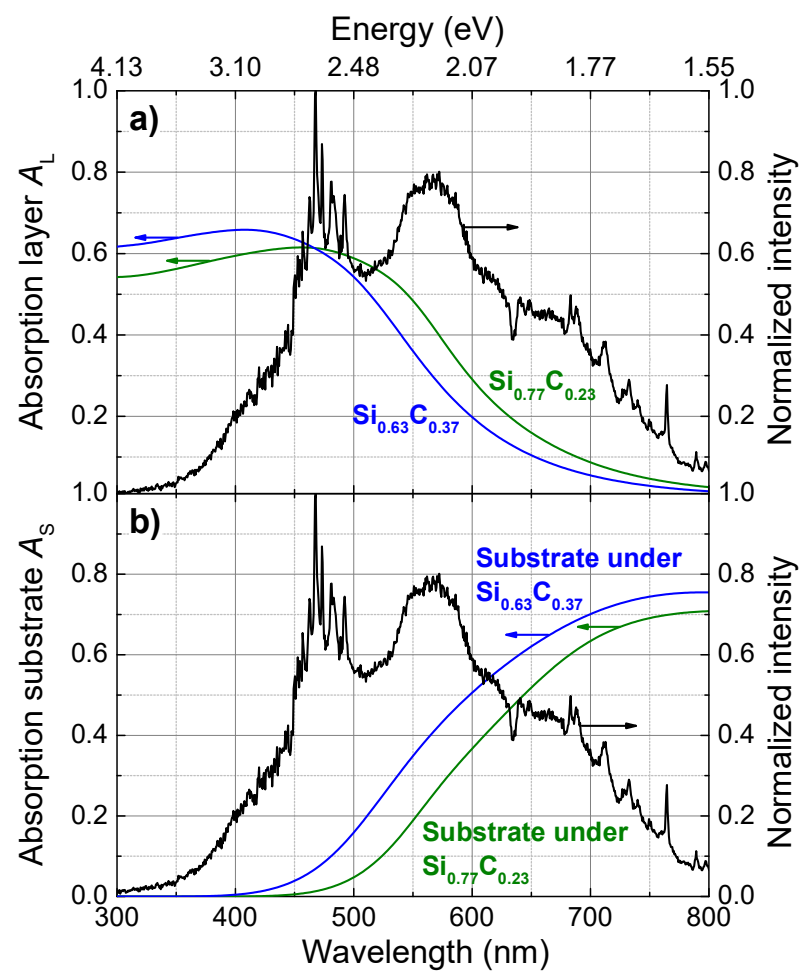

Figure 11: The normalized emission spectrum of the Xe lamps (black) used for FLA is plotted with the absorption of the layers $\mathrm{Si}_{0.77} \mathrm{C}_{0.23}\left(A_{\mathrm{L}-77}\right.$, green) and $\mathrm{Si}_{0.63} \mathrm{C}_{0.37}\left(A_{\mathrm{L}-63}\right.$, blue $)$ in a) and the absorption of the substrate under the $\mathrm{Si}_{0.77} \mathrm{C}_{0.23}\left(A_{\mathrm{S}-77,}\right.$ green) and $\mathrm{Si}_{0.63} \mathrm{C}_{0.37}\left(A_{\mathrm{S}-63}\right.$, blue) layer in b).

[18] (right-hand ordinate). Figure $11 \mathrm{~b}$ ) presents the calculated $T_{\mathrm{i}}(\lambda)$ for $\mathrm{Si}_{0.63} \mathrm{C}_{0.37}$ (blue) and $\mathrm{Si}_{0.77} \mathrm{C}_{0.23}$ (green) (left-hand ordinate), which correspond to the absorption in the Si substrate $A_{\mathrm{s}-\mathrm{i}}(\lambda)$ under the $\mathrm{Si}_{0.63} \mathrm{C}_{0.37}$ 
Published in: Journal of Applied Physics, vol. 120, p. 105103, 2016.

DOI: $10.1063 / 1.4962262$

and the $\mathrm{Si}_{0.77} \mathrm{C}_{0.23}$ layer $\left(T_{\mathrm{i}}(\lambda)=A_{\mathrm{S}-\mathrm{i}}(\lambda)\right)$. Figure 11 a) shows that $A_{\mathrm{L}-77}(\lambda)>A_{\mathrm{L}-63}(\lambda)$ in the spectral range of high intensity of the Xe lamps. Correspondingly, more light is transmitted and therefore absorbed in the $\mathrm{Si}$ substrate in the case of the $\mathrm{Si}_{0.63} \mathrm{C}_{0.37}$ sample $\left(A_{\mathrm{S}-63}(\lambda)>A_{\mathrm{S}-77}(\lambda)\right)$. To quantify this observation, the fraction of $I(\lambda)$ absorbed in the layer was calculated by

$$
\chi_{\mathrm{L}-\mathrm{i}}=\frac{\int A_{\mathrm{L}-\mathrm{i}}(\lambda) I(\lambda) d \lambda}{\int I(\lambda) d \lambda}
$$

and in the substrate by

$$
\chi_{\mathrm{S}-\mathrm{i}}=\frac{\int A_{\mathrm{S}-\mathrm{i}}(\lambda) I(\lambda) d \lambda}{\int I(\lambda) d \lambda}
$$

to be $\chi_{\mathrm{L}-63}=32 \%$ and $\chi_{\mathrm{L}-77}=37 \%$ in the layers and $\chi_{\mathrm{S}-63}=39 \%$ and $\chi_{\mathrm{S}-77}=30 \%$ in the substrate. It follows that the absorption behavior of the layers alone cannot be the reason for the stronger crystallization in $\mathrm{Si}_{0.63} \mathrm{C}_{0.37}$ compared with that in $\mathrm{Si}_{0.77} \mathrm{C}_{0.23}$. However, the overall absorption $\chi_{\mathrm{i}}={ }^{\circ} \chi_{\mathrm{L}-\mathrm{i}}+\chi_{\mathrm{S}-\mathrm{i}}$ is higher in the $\mathrm{Si}_{0.63} \mathrm{C}_{0.37}$ sample $\left(\chi_{63}={ }^{\circ} 71 \%\right)$ than in the $\mathrm{a}-\mathrm{Si}_{0.77} \mathrm{C}_{0.23}$ sample $\left(\chi_{77}={ }^{\circ} 67 \%\right)$. Therefore, it is possible that the absorption in the substrate can act as a significant heat source for the layer on top. To verify this reasoning, we performed a further experiment with the same a- $\mathrm{Si}_{0.63} \mathrm{C}_{0.37}: \mathrm{H}$ and a- $\mathrm{Si}_{0.77} \mathrm{C}_{0.23}: \mathrm{H}$ layers deposited on quartz instead of Si substrate because quartz shows negligible absorption in the optical wavelength range.

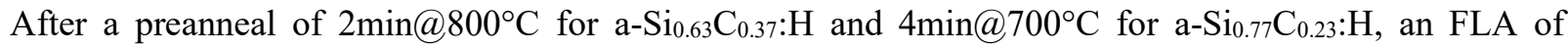
20ms@47 J/cm² was performed for both samples. The Si NC size derived from GIXRD measurements was $(14.6 \pm 0.5) \mathrm{nm}$ for $\mathrm{Si}_{0.63} \mathrm{C}_{0.37}$ and $(18.6 \pm 0.5) \mathrm{nm}$ and thus significantly higher for $\mathrm{Si}_{0.77} \mathrm{C}_{0.23}$. This result agrees with our expectation of an increase in Si NC size with increasing Si content and suggests that strong absorption in the substrate promotes film crystallization. 
Published in: Journal of Applied Physics, vol. 120, p. 105103, 2016.

DOI: $10.1063 / 1.4962262$

(ii) Because $\mathrm{Si}_{0.63} \mathrm{C}_{0.37}$ was preannealed at higher temperatures than $\mathrm{Si}_{0.77} \mathrm{C}_{0.23}$, the formation of more crystallization seeds during preannealing in $\mathrm{Si}_{0.63} \mathrm{C}_{0.37}$ samples compared with $\mathrm{Si}_{0.77} \mathrm{C}_{0.23}$ could be the result. However, even if this was the case, this effect would only lead to an increased number of $\mathrm{Si}$ and $\mathrm{SiC}$ crystallites in $\mathrm{Si}_{0.63} \mathrm{C}_{0.37}$ samples compared with the number observed in $\mathrm{Si}_{0.77} \mathrm{C}_{0.23}$ samples, as discussed in the previous section, but would not explain the observed difference in NC sizes. Thus, the preanneal temperature is not the reason for the crystallization behavior.

(iii) As shown in the inset of Figure $8 \mathrm{~b}$ ) and d), the $\mathrm{Si}-\mathrm{H}$ vibrational mode of $\mathrm{Si}_{0.63} \mathrm{C}_{0.37}$ (blue) after preannealing is stronger than that in $\mathrm{Si}_{0.77} \mathrm{C}_{0.23}$ (red), indicating more remaining hydrogen in $\mathrm{Si}_{0.63} \mathrm{C}_{0.37}$ samples after preannealing than in $\mathrm{Si}_{0.77} \mathrm{C}_{0.23}$. This higher amount of hydrogen could result in enhanced $\mathrm{Si}$ diffusion in $\mathrm{Si}_{0.63} \mathrm{C}_{0.37}$ compared with that in $\mathrm{Si}_{0.77} \mathrm{C}_{0.23}$, leading to the formation of larger clusters at the same flash energy and therefore to larger $\mathrm{Si} \mathrm{NC}$ in $\mathrm{Si}_{0.63} \mathrm{C}_{0.37}$ samples. Lanckmans et al. [44] observed a similar effect of $\mathrm{H}$ on the mobility of $\mathrm{Cu}^{+}$in PECVD deposited a-SiC:H layers.

We consider both increased hydrogen content after preannealing and substrate absorption of FLA light to be probable explanations for the unexpected improvement in Si crystallization with decreasing Si content. 
Published in: Journal of Applied Physics, vol. 120, p. 105103, 2016.

DOI: $10.1063 / 1.4962262$

\section{V) CONCLUSIONS}

A comparison of $\mathrm{Si}_{x} \mathrm{C}_{1-x}$ layers with varying compositions $(x=0.50, x=0.63$ and $x=0.77)$ treated by RTA and by FLA reveals that the reduction from an annealing time of $2 \mathrm{~min}$ to $20 \mathrm{~ms}$ leads to surprisingly similar crystallization results, as evidenced by GIXRD and FTIR measurements. We showed that a preanneal step for $\mathrm{H}$ effusion is needed to avoid blistering during FLA, whereas for RTA the ramping-up time is sufficiently long for $\mathrm{H}$ effusion without blistering. The $\mathrm{H}$ effusion temperature increases with decreasing Si content in the layer and exceeds the maximum possible preanneal temperature in the FLA system for $\mathrm{Si}_{0.50} \mathrm{C}_{0.50}$ samples. Therefore, successful FLA was only possible for $\mathrm{Si}_{0.63} \mathrm{C}_{0.37}$ and $\mathrm{Si}_{0.77} \mathrm{C}_{0.23}$ samples.

For both $\mathrm{Si}_{0.63} \mathrm{C}_{0.37}$ and $\mathrm{Si}_{0.77} \mathrm{C}_{0.23}$ layers, the $\mathrm{Si} \mathrm{NC}$ lose their randomly distributed orientation and grain size above a certain FLA energy ( $40 \mathrm{~J} / \mathrm{cm}^{2}$ and $47 \mathrm{~J} / \mathrm{cm}^{2}$, respectively), whereas the orientation of the $\mathrm{SiC} \mathrm{NC}$ remain random for all flash energies. Because this Si grain orientation require highly mobile Si atoms, we suggest that a Si liquid phase is formed at high flash energies, and we take the onset of the Si grain orientation process as an upper energy limit for solid-phase crystallization by FLA.

The $\mathrm{Si}_{0.63} \mathrm{C}_{0.37}$ show larger $\mathrm{Si}$ and $\mathrm{SiC} \mathrm{NC}$ sizes than the $\mathrm{Si}_{0.77} \mathrm{C}_{0.23}$ samples for the same FLA energy over the entire energy range. One possible explanation for this trend is the amount of hydrogen remaining in the layers after the preanneal step. This amount is higher for $\mathrm{Si}_{0.63} \mathrm{C}_{0.37}$ than for $\mathrm{Si}_{0.77} \mathrm{C}_{0.23}$ layers and could facilitate diffusion and therefore crystallization in the $\mathrm{Si}_{0.63} \mathrm{C}_{0.37}$ layers. Another explanation is the different absorption behavior of the $\mathrm{Si}_{0.63} \mathrm{C}_{0.37}$ and $\mathrm{Si}_{0.77} \mathrm{C}_{0.23}$ layers on $\mathrm{Si}$ substrates. Taking into account the absorption in both the layer and the substrate, our calculation results in higher absorption in the $\mathrm{Si}_{0.63} \mathrm{C}_{0.37}: \mathrm{H}$ sample $\left(\chi_{63}={ }^{\circ} 71 \%\right)$ than in the $\mathrm{a}-\mathrm{Si}_{0.77} \mathrm{C}_{0.23}: \mathrm{H}$ sample $\left(\chi_{77}={ }^{\circ} 67 \%\right)$. This discrepancy could cause a higher sample temperature in $\mathrm{Si}_{0.63} \mathrm{C}_{0.37}: \mathrm{H}$ than in $\mathrm{a}-\mathrm{Si}_{0.77} \mathrm{C}_{0.23}: \mathrm{H}$ samples and therefore the formation of larger $\mathrm{NC}$.

A very promising observation is the reduction of $\mathrm{SiC}$ crystallization as a result of switching from RTA to FLA. This reduction was explained in terms of nucleation and crystal growth and led to the formation of fewer SiC NC during FLA compared with the number observed in RTA samples. FLA is a promising 
Published in: Journal of Applied Physics, vol. 120, p. 105103, 2016.

DOI: $10.1063 / 1.4962262$

method for synthesizing $\mathrm{Si} \mathrm{NC}$ embedded in less crystalline $\mathrm{SiC}$, providing a route towards developing $\mathrm{Si}$ $\mathrm{NC}$ in a-SiC, which are expected to be of higher electronic quality and thus enable the fabrication of better Si NC solar cells. 
Published in: Journal of Applied Physics, vol. 120, p. 105103, 2016.

DOI: $10.1063 / 1.4962262$

\section{VI) ACKNOWLEDGEMENTS}

The authors wish to thank Philipp Barth, Mira Kwiatkowska, Antonio Leimenstoll and Felix Schätzle for help with sample processing and Jutta Zielonka for SEM measurements. The research leading to these results has received funding from the Protestant Academic Foundation Villigst, Germany. 
Published in: Journal of Applied Physics, vol. 120, p. 105103, 2016.

DOI: $10.1063 / 1.4962262$

1. Green, M.A., et al., Solar cell efficiency tables (version 47). Progress in Photovoltaics: Research and Applications, 2016. 24(1): p. 3-11.

2. Janz, S., P. Löper, and M. Schnabel, Silicon nanocrystals produced by solid phase crystallisation of superlattices for photovoltaic applications. Material Science and Engineering B, 2012: p. 542-50.

3. Conibeer, G., et al., Silicon nanostructures for third generation photovoltaic solar cells. Thin Solid Films, 2006. 511-2: p. 654-62.

4. Harris, G.L., Properties of silicon carbide, ed. G.L. Harris. 1995, London, UK: INSPEC, the Institution of Electrical Engineers. 282.

5. Schnabel, M., et al., Charge transport in nanocrystalline SiC with and without embedded Si nanocrystals. Physical Review B, 2015. 91(19): p. 195317.

6. Summonte, C., et al., Silicon nanocrystals in carbide matrix. Solar Energy Materials and Solar Cells, 2014. 128: p. 138-49.

7. Song, D., et al., Structural characterization of annealed Si(1-x)C(x)/SiC multilayers targeting formation of Si nanocrystals in a SiC matrix. Journal of Applied Physics, 2008. 103: p. 083544

8. Kurokawa, Y., et al. Effects of nitrogen on the electrical properties of Si quantum dots superlattice using a-SiC Matrix. in Proceedings of the 24th European Photovoltaic Solar Energy Conference. 2009. Hamburg, Germany.

9. Ouadfel, M.A., et al., Si-rich a-Si1- $x C x$ thin films by d.c. magnetron co-sputtering of silicon and silicon carbide: Structural and optical properties. Applied Surface Science, 2013. 265: p. 94-100.

10. Schnabel, M., et al., Self-assembled silicon nanocrystal arrays for photovoltaics. physica status solidi (a), 2015. 212(8): p. 1649-1661.

11. Janz, S., P. Löper, and M. Schnabel, Silicon nanocrystals produced by solid phase crystallisation of superlattices for photovoltaic applications. Materials Science and Engineering B, 2013. 178(9): p. 542-50.

12. Weiss, C., et al., Structural and optical properties of silicon nanocrystals embedded in silicon carbide: Comparison of single layers and multilayer structures. Applied Surface Science, 2015. 351: p. 550-557.

13. Wan, Z.Y., et al., Rapid thermal annealing and crystallization mechanisms study of silicon nanocrystal in silicon carbide matrix. Nanoscale Research Letters, 2011. 6(129): p. 1-7.

14. Ohdaira, K., et al., Explosive crystallization of amorphous silicon films by flash lamp annealing. Journal of Applied Physics, 2009. 106(4): p. 044907.

15. Ohdaira, K., 10- $\mu m$-thick polycrystalline silicon films formed by flash lamp annealing, in PVSEC. 2013: Paris.

16. Skorupa, W., et al., Advanced thermal processing of semiconductor materials in the millisecond range. Vacuum, 2005. 78(2-4): p. 673-677.

17. Löper, P., Silicon Nanostructures for Photovoltaics, in Technical Faculty. 2013, University of Freiburg: Freiburg. p. 158.

18. Prucnal, S., et al. Solar Cell Emitters Fabricated by Flash Lamp Millisecond Annealing. in Proceedings of the 8th International Conference Ion Implantation and Other Applications of Ions and Electrons. 2011. Dolny, Poland.

19. Skorupa, W., et al., Advanced Thermal Processing of Ultrashallow Implanted Junctions Using Flash Lamp Annealing. Journal of The Electrochemical Society, 2005. 152(6): p. G436-G440.

20. Weiss, C., et al. Novel Silicon Nanocrystal Materials for Photovoltaic Applications. in Proceedings of the 28th European PV Solar Energy Conference and Exhibition. 2013. Paris, France.

21. Peter, S., et al., FTIR analysis of a-SiCN:H films deposited by PECVD. Vacuum, 2013. 98(0): p. 8187. 
Published in: Journal of Applied Physics, vol. 120, p. 105103, 2016.

DOI: $10.1063 / 1.4962262$

22. Wieder, H., M. Cardona, and C.R. Guarnieri, Vibrational spectrum of hydrogenated amorphous Si-C films Physica Status Solidi B, 1979. 92(99): p. 99-112.

23. McKenzie, D.R., Infrared absorption and bonding in amorphous hydrogenated silicon-carbon alloys. Journal of Physics D: Applied Physics, 1985. 18(9): p. 1935-48.

24. Kerdiles, S., et al., Low temperature deposition of nanocrystalline silicon carbide thin films. Applied Physics Letters, 2000. 76(17): p. 2373-2375.

25. Calcagno, L., et al., Crystallisation mechanism of amorphous silicon carbide. Applied Surface Science, 2001. 184(1-4): p. 123-127.

26. Tsu, D.V., G. Lucovsky, and M.J. Mantini, Local anatomic structure in thin films of silicon nitride and silicon diimide produced by remote plasma-enhanced chemical-vapor deposition. Physical Review B, 1986. 33(10): p. 7069-76.

27. Giorgis, F., et al., Optical, structural and electrical properties of device-quality hydrogenated amorphous silicon-nitrogen films deposited by plasma-enhanced chemical vapour deposition. Philosophical Magazine Part B, 1998. 77(4): p. 925-944.

28. King, S.W., et al., Mass and bond density measurements for PECVD a-SiC $: H$ thin films using Fourier transform-infrared spectroscopy. Journal of Non-Crystalline Solids, 2011. 357: p. 360215.

29. Musumeci, P., L. Calcagno, and A. Makhtari, Relaxation phenomena in keV-ion implanted hydrogenated amorphous silicon carbide. Materials Science and Engineering: A, 1998. 253(12): p. 296-300.

30. Guinier, A., et al., X-Ray Diffraction in Crystals, Imperfect Crystals, and Amorphous Bodies. Vol. 17. 1964.

31. Hull, R., Properties of crystalline silicon. EMIS datareviews series. 1999, London: INSPEC, the Institution of Electrical Engineers.

32. Lucovsky, G., Chemical effects on the frequencies of Si-H vibrations in amorphous solids. Solid State Communications, 1979. 29(8): p. 571-6.

33. Gat, E., et al., $A$ study of the effect of composition on the microstructural evolution of aSixC1-x: H PECVD films: IR absorption and XPS characterizations. Journal of Materials Research, 1992. 7(09): p. 2478-2487.

34. Meyer, K., Physikalisch-chemische Kristallographie. Vol. 2. 1977, Leipzig: VEB Deutscher Verlag für Grundstoffindustrie 368.

35. Smith, M., et al., Modelling of flash-lamp-induced crystallization of amorphous silicon thin films on glass. Journal of Crystal Growth, 2005. 285(1-2): p. 249-260.

36. Wei, L., et al., Heat conduction in silicon thin films: Effect of microstructure. Journal of Materials Research, 1995. 10(08): p. 1889-1896.

37. Lee, S.G., et al., Low Dielectric Constant 3MS $\alpha$-SiC:H as Cu Diffusion Barrier Layer in Cu Dual Damascene Process. Japanese Journal of Applied Physics, 2001. 40(4S): p. 2663.

38. Sarro, P.M., Silicon carbide as a new MEMS technology. Sensors and Actuators A: Physical, 2000. 82(1-3): p. 210-218.

39. Verrall, R.A., M.D. Vlajic, and V.D. Krstic, Silicon carbide as an inert-matrix for a thermal reactor fuel. Journal of Nuclear Materials, 1999. 274(1-2): p. 54-60.

40. Patnaik, P., Handbook of inorganic chemicals. 2003: McGraw-Hill.

41. Wesch, W., Silicon carbide: synthesis and processing. Nuclear Instruments and Methods in Physics Research Section B: Beam Interactions with Materials and Atoms, 1996. 116(1-4): p. 305-321.

42. Grigoriev, I.S. and E.Z. Meilikhov, Handbook of physical quantities. 1997: CRC Press LLC.

43. Jellison, G.E., Jr., Spectroscopic ellipsometry data analysis: measured versus calculated quantities. Thin Solid Films, 1998. 313-4: p. 33-9. 
Published in: Journal of Applied Physics, vol. 120, p. 105103, 2016.

DOI: $10.1063 / 1.4962262$

44. Lanckmans, F., B. Brijs, and K. Maex, The role of $\mathrm{H}$ in the $\mathrm{Cu}+$ drift diffusion in plasmadeposited a-SiC:H. Journal of Physics: Condensed Matter, 2002. 14(13): p. 3565. 